\title{
Aging, Health, and the Indigenous People of North America
}

\author{
Lori L. Jervis
}

Published online: 3 November 2010

(C) Springer Science+Business Media, LLC 2010

Although the articles for this special issue on Native North American elders cover a diverse array of topics, approaches, and geographical areas, this issue was motivated by a single desire: to gather together in one venue a collection of varied disciplinary approaches to contemporary social and cultural research with older American Indian, Alaska Native, and First Nations people. These Native elders constitute a relatively small, but rapidly growing, population (John 1996). The importance of elders to Native communities, however, belies these small numbers. Elders have traditionally been leaders, keepers of history and cultural knowledge, and socializers of the younger generation (Red Horse 1983; Red Horse 1980; Weibel-Orlando 1989). In many communities, these roles continue, although they may be challenged in the face of contemporary pressures. Despite elders' symbolic and practical importance in many tribal communities, current empirical research with this group remains limited. Indeed, there are many important elder-related topics that have received scant research attention, although they are of keen interest to communities themselves. This special issue is one step toward rectifying that discrepancy.

Most of the manuscripts here were presented as part of the 2009 Association for Anthropology and Gerontology Annual Conference held at the University of Oklahoma. The theme of the meeting was "Aging and the Indigenous People of North America." The conference brought together a variety of scholars and researchers working in this area. As demonstrated below, much of the research currently being conducted focuses on health issues. Given the many health disparities faced by Native people in general and older Native people in particular (Dixon and Roubideaux 2001), it is not surprising that healthrelated issues are an especially pertinent aspect of the aging experience for Native elders. These disparities and systemic health system inadequacies may be further exacerbated when Western biomedical constructs come into conflict with indigenous illness conceptualizations, potentially posing challenges for elders, traditional healers, and biomedically oriented health care practitioners (Kleinman 1980).

Two articles in this special issue concentrate on Native elders' perspectives on health issues. Henderson focuses on an urgent problem in many Native communities, the diabetes

L. L. Jervis $(\bowtie)$

University of Oklahoma, Norman, OK, USA

e-mail: lori.jervis@ou.edu 
epidemic. She examines the effect of Oklahoma Native elders' ethnic identities on attitudes toward biomedical diabetic care-seeking and adherence. She finds that elders with more indigenous identities are less likely to value, seek, or adhere to diabetic care than elders whose identities are more akin to the dominant culture. This suggests that health care providers would be well served to consider the "intra-cultural" differences that may exist among their Native patients and how these may or may not affect care.

Hulko and colleagues' article on dementia utilizes a community-based approach to explore the sensitive topic of memory loss in three First Nations communities. Here, the authors describe the process by which they worked with the communities to carry out their research, as well as their particular qualitative approach which included sharing circles and in-depth interviews. They identify two different views of memory loss among the Secwepemc elders (i.e., the traditional and the white way), providing examples of each. To date, few published reports describe how Native elders themselves understand memory issues, so this article provides a useful early look at an important issue.

None of the above topics have an extensive literature, and Goins and Pilkerton report on yet another health-related topic with a very limited literature among older Natives: comorbidity. In their study, the authors find that American Indians in the southeastern region of the U.S. suffer higher prevalences of several chronic conditions than does the general US population. Further, the majority of Goins and Pilkerton's Native elder sample suffered from comorbid conditions. Given the well-known limitations of the overstretched Indian Health Service (Dixon and Roubideaux 2001) in dealing with chronic conditions (and the high costs associated with treating both chronic and comorbid conditions), this study raises intriguing questions about whether the system will be able to keep up with a clientele whose life expectancy is projected to increase considerably over the coming decades (John 1996).

Given that most care to ill and disabled elders is provided by informal caregivers (Hennessy and John 1995, 1996; Navaie-Waliser et al. 2002), Jervis, Boland, and Fickenscher's examination of the provision of care by family members to Native elders helps explicate another phenomenon about which we know little. The authors find that in the northern plains reservation context where their research was conducted, family members report low level of caregiving burden while maintaining quite positive attitudes toward assisting elders. These results held true whether examined qualitatively or quantitatively. Such a finding differs considerably from that one would typically find for dominant culture caregiving groups. In explaining this finding, Jervis and colleagues highlight the importance of cultural attitudes toward elders and the strong relationships of reciprocity that occur in this community. They conclude that elder care occurs in a complex web of intergenerational, reciprocal exchanges of assistance that may serve to ease feelings of burden, while positive cultural notions regarding elders and elder care may increase caregiving satisfaction. In this northern plains community, it is a common practice for grandparents to raise grandchildren for reasons ranging from cultural tradition to family crisis. In turn, grandchildren often describe feelings of gratitude and the desire to "return the favor" to the elder.

Focusing on a different aspect of caregiving, Cross, Day, and Byers' manuscript on Indian grandparents caring for grandchildren examines an area on which there is little research but which is quite salient in Native communities, for older and younger people alike. The authors find several motivations for the provision of care to grandchildren among elders in Michigan tribal communities, with parental substance abuse especially common. Grandparents are motivated by the goal of keeping families together, heightened by the trauma that they themselves experienced as children in the boarding schools that so often 
broke up Native families. Many grandparents either have no knowledge of the Indian Child Welfare Act or believe it will not help them. These grandparents, then, bear a major responsibility for their grandchildren's care without adequate legal protections, a potentially highly problematic situation.

Finally, Jordan examines what successful aging means to Alaska Natives, both to elders and non-elders. This is an important topic because it focuses not only on decline, but on what it means to live life well into late life for Native people, a seldom explored topic. Here, participants do not define successful aging merely in terms of good physical health, but also in terms of being active in the community, passing down knowledge and wisdom, and taking responsibility for one's own health and wellbeing. Poor aging, conversely, entails lack of responsibility, being unable to handle alcohol, not being active in the community, and giving up on oneself. These cultural models of aging are powerful because they offer "ideals" that may potentially inform the aspirations and behavior of younger generations, as well as cultural models of what to avoid.

Hence, this body of scholarship demonstrates some of the diverse topic areas and approaches that are the focus of social and cultural research with Native elders today. Continued emphasis on elders' perspectives, areas of strengths in addition to challenges, and methodologies that incorporate and reflect community concerns and priorities will continue to broaden and strengthen this field into the future.

\section{References}

Dixon, M., \& Roubideaux, Y. (2001). Introduction. In M. Dixon \& Y. Roubideaux (Eds.), Promises to keep: Public health policy for American Indian and Alaska Natives in the 21st Century (pp. xix-xxi). Washington: American Public Health Association.

Hennessy, C. H., \& John, R. (1995). The interpretation of burden among Pueblo Indian caregivers. Journal of Aging Studies, 9(3), 215-229.

Hennessy, C. H., \& John, R. (1996). American Indian family caregivers' perceptions of burden and needed support services. Journal of Applied Gerontology, 15(3), 275-293.

John, R. (1996). Demography of American Indian elders: social, economic, and health status. In G. D. Sandefur, R. R. Rindfuss, \& B. Cohen (Eds.), Changing numbers, changing needs: American Indian demography and public health (pp. 218-231). Washington: National Academy Press.

Kleinman, A. (1980). Patients and healers in the context of culture: An exploration of the borderland between anthropology, medicine, and psychiatry. Berkeley: University of California Press.

Navaie-Waliser, M., Spriggs, A., \& Feldman, P. H. (2002). Informal caregiving: differential experiences by gender. Medical Care, 40(2), 1249-1259.

Red Horse, J. G. (1980). Family structure and value orientation in American Indians. Social Casework: The Journal of Contemporary Social Work, 462-467.

Red Horse, J. (1983). Indian family values and experiences. In G. J. Powell (Ed.), The psychosocial development of minority group children (pp. 258-271). New York: Brunner/Mazel.

Weibel-Orlando, J. (1989). Elders and elderlies: well-being in Indian old age. American Indian Culture and Research Journal, $13(3$ \& 4), 149-170. 